\title{
Pattern of utilization of ante-natal and delivery services in a semi-urban community of North-Central Nigeria.
}

\author{
Jimoh Maryam Abimbola ${ }^{1}$, Akande Tanimola Makanjuola ${ }^{1}$, Salaudeen Adekunle Ganiyu, \\ Uthman Mohammed Mubashir Babatunde ${ }^{1}$, Durowade Kabir Adekunle ${ }^{2}$, Aremu Ayodele Olatayo ${ }^{3}$
}

1. Department of Epidemiology and Community Health, University of Ilorin Teaching Hospital, Ilorin, Nigeria 2. Department of Community Medicine, Federal Teaching Hospital, Ido-Ekiti, Nigeria

3. Department of Community Medicine, Bowen University Teaching Hospital, Ogbomosho, Nigeria drcapotee@ yahoo.com

\begin{abstract}
:
Background: Nigeria accounts for only $2 \%$ of the world's population, but contributes up to $10 \%$ of the global estimates of maternal deaths. The study assesses the utilization of antenatal and delivery services by women of reproductive age in Afon community.

Methodology: It was a descriptive cross-sectional study that collected both quantitative and qualitative data using semi-structured interviewer administered questionnaire and focus group discussions (FGD). Interviews were house-hold based. FGD had two homogenous groups. Data was analysed using Epi-info version 3.5.1 software package. Level of statistical significance was set at $\mathrm{p}<0.05$.

Results: There was a high level of utilization of antenatal/delivery services in the community. Barriers to utilization of ANC/ delivery services include lack of money, distance from health facility, long waiting time, poor attitude of health workers and no permission from husbands. Level of education and employment status were significantly associated with utilization of ANC/ delivery services.

Conclusion: Girl- child education and women empowerment are required to improve utilization of services. Ante-natal care providers need to be trained to improve quality of care in the discharge of their duties.
\end{abstract}

Keywords: Utilization, antenatal services, Nigeria

DOI: http://dx.doi.org/10.4314/ahs.v16i4.12

Cite as: Abimbola JM, Makanjuola AT, Ganiyu SA, Babatunde UMM, Adekunle DK, Olatayo AA. Pattern of utilization of ante-natal and delivery services in a semi-urban community, north-central Nigeria. Afri Health Sci 2016;16(4): 962-971. http://dx.doi.org/10.4314/abs. v16i4.12

\section{Introduction:}

The world demographic profile shows that women and children together constitute a high proportion of the population accounting for over 60 percent of the population in the developing countries. ${ }^{1}$ Women, especially those of reproductive age group and children not only constitute a large group but also are the most vulnerable and "special risk" members of the society. ${ }^{2,3}$ The risk is connected to childbearing in the case of the women; survival, growth and development in the case of infants and children. $^{2}$
Corresponding author:
Jimoh Maryam Abimbola,
Department of Epidemiology
and Community Health,
University of Ilorin Teaching Hospital,
Ilorin, Nigeria
Tel: +2348035769378
E-mail: mazubair2000@yahoo.com

African Health Sciences Vol 16 Issue 4, December, 2016
Available statistics show that approximately one thousand women die every day from preventable causes related to pregnancy and childbirth and nearly $40 \%$ of all under-five child deaths are among newborn infants i.e. babies in their first 28 days of life every year. ${ }^{4}$ Three quarters of these new born deaths occur in the first week of life and $99 \%$ of all maternal deaths occur in developing countries. $^{5}$

Pregnancy and childbirth and their consequences are still the leading causes of death, disease and disability among women of reproductive age in developing countries more than any other single health problem. ${ }^{6}$ Worldwide, an estimated half a million women die each year from complications of pregnancies and child birth ${ }^{7}$ Of this, 55,000 maternal deaths occur in Nigeria alone. Thus, although Nigeria accounts for only $2 \%$ of the world's population, it contributes $10 \%$ of the global estimates of maternal deaths and most of these deaths could have been prevented. 
Nigeria loses 145 women of childbearing age everyday making her the second largest contributor to the maternal mortality rate in the world after India. ${ }^{8}$ For every woman who dies of maternal causes, at least six newborns die and a further four babies are stillborn. ${ }^{9}$ In Nigeria alone, 284,000 newborns die every year- that is, 778 deaths each day ${ }^{9}$ Many of these deaths occur at home and are therefore unseen within and unaccounted for in official statistics. Each year, 23,000 Nigerian newborns die of tetanus which is eminently preventable with feasible, low cost immunisation of women. ${ }^{9}$ The majority of the newborn deaths occur within the first week of life, reflecting the inextricable link between newborn survival and quality of maternal care. ${ }^{?}$

Worldwide, $34 \%$ of deliveries have no skilled attendant. This means 45 million births occur at home without skilled health personnel each year. ${ }^{10}$ In Nigeria, only $39 \%$ of births in the five years preceding the 2008 demographic and health survey were assisted by a skilled health worker (doctor, nurse, midwife or auxiliary nurse/midwife). Also, 3 in 5, that is 62 percent of births occur at home with nineteen percent of birth assisted by a relative or other person and an equal proportion of births were attended to by no one. ${ }^{11}$

Many reasons have been given for the high maternal and infant mortality in most of the developing countries such as poor access to quality health care services. However, even where the services are available studies have shown low utilization of these services. ${ }^{12}$ This will definitely assist the policy makers to put strategies in place to improve utilization. Thus, there is an urgent need to understand the preference of people and the various factors that influence their preferences. This survey was conducted in a typical semi-urban community in Kwara State, North Central Nigeria to provide more literature on utilization pattern of antenatal and delivery services in this part of the state and possibly identify gaps in service delivery. Thus, provides information that can assist policy makers with improvement in maternal and child health indices.

It is the hope of the researcher that findings from this study will assist policy makers to put strategies in place to plan appropriate programs and improve utilization. This is very crucial if the targets of the $5^{\text {th }}$ millennium development goal are to be achieved in Nigeria. It is a descriptive cross sectional study designed to assess the knowledge, attitude and pattern of utilization of antena- tal and delivery services by women of reproductive age in Afon community, Kwara State, Nigeria.

\section{Methodology:}

Afon town, a semi-urban community, is the headquarters of Asa LGA and is about 30 kilometers from Ilorin, the Kwara State capital in North-Central Nigeria. It is bounded in the North by Ogele town, in the West by Aboto town, in the East by Laduba and in the South by Foko village. The total population of Afon community based on household enumeration done in 2011 was 3497 with 1338 males and 1370 females. There were 229 houses and a total of 455 households in the town. The people are predominantly Yorubas with pockets of other tribes such as Fulani, Nupe, and Hausa. They are mainly peasant farmers and traders.

There are four health facilities in Afon town: 2 public and 2 private. The public facilities are the General Hospital Afon and the District Health Unit, Afon owned by the state and the local governments respectively. All the health facilities render antenatal, delivery and postnatal services among others.

The study population for the quantitative component of the study included all women within the reproductive age of 15-49 years living permanently in Afon community who have been pregnant or have had a baby in the last five years. Both men and women of reproductive age group i.e. 15-59 years and 15-49 years respectively living permanently in Afon community constituted the study population for the qualitative aspect of the study.

This study was descriptive cross sectional and designed to assess the knowledge, attitude and pattern of utilization of antenatal and delivery services in Afon community. The survey was conducted between August and October 2011; and both quantitative data using pre-tested interviewer administered semi-structured questionnaire and qualitative data using focus group discussions were collected.

The questionnaire contained 4 sections with questions to elicit socio-demograhic characteristics of respondents, their knowledge, attitude and pattern of utilization of antenatal and delivery services as well as factors influencing utilization of services. The FGD guide contained 13 questions that were capable of generating robust discussion among participants on the topic rather than yes or 
no responses. $10 \%$ of the questionnaire was pre-tested at Oloje Community, about 60 kilometres from Afon, in Ilorin East LGA to ascertain its validity and correct for any inconsistencies. Four undergraduates from University of Ilorin and Al-Hikmah were recruited and trained as research assistants to conduct interviews. One of them was further trained to assist in note taking during the FGD. The sample size was calculated using Fisher's formula which gave a total of 275 respondents for the quantitative aspect of the research.

All the 455 households in the community were sampled for the study. All the houses were visited and all the women that satisfied the eligibility criteria and consented were interviewed. All households were used because of the limited number of households bearing in mind the sample size and considering the fact that some of them did not have eligible respondents. Data was analysed using Epi-Info version 3.5.1 software package and relevant summary statistics were generated. Chi-square test was used to test hypothesis for associations between categorical variables (socio-demographic variables, awareness and utilization of antenatal and delivery services). Level of significance was set at p-value less than 0.05.

For the qualitative aspect of the study, Focus Group Discussion (FGD) was done. Subjects for the FGD were selected by purposive sampling method. Consenting wom- en and men of reproductive age group i.e. 15-49 years and 15-59 years respectively living permanently in Afon community were selected.

The FGD consisted of two homogenous groups - males and females within the reproductive age groups. A total of four sessions FGD were conducted with two for each group. Each group consisted of ten persons and each session lasted for about one hour to one and half hours. FGD recorded sessions on tape was transcribed into notes which were then processed, coded and interpreted using detailed content analysis method. Informed consent was obtained from the respondents before the interview and all information obtained was treated with utmost confidentiality.

\section{Results}

As shown in Table 1, majority of the respondents, 88 (31.1\%) were within the 25-29 age group with a mean age of $27.9 \pm 6.0$ years while $273(96.5 \%)$ were married. More than three-quarters of the respondents, 247 (87.3\%) had four children or less. The mean number of children was 5.1 while the number of children ranged from 1-10. More than three-quarters of the respondents were Yorubas $(222(78.4 \%))$ and Muslims $257(90.8 \%)$ respectively. Less than a quarter, 50(17.7\%), had no formal education while less than half, 114(40.3\%), of the respondents had secondary education.

Table 1: Socio-demographic characteristics of the respondents. $N=283$

\begin{tabular}{|c|c|c|c|}
\hline $\begin{array}{l}\text { Variables } \\
\text { Age(years) }\end{array}$ & Frequency (\%) & $\begin{array}{l}\text { Variable } \\
\text { Occupation }\end{array}$ & Frequency (\%) \\
\hline $15-19$ & $11(3.9)$ & Trading & $119(51.1)$ \\
\hline $20-24$ & $83(29.3)$ & Artisan & $78(33.5)$ \\
\hline $25-29$ & $88(31.1)$ & Civil Servant & $23(9.9)$ \\
\hline $30-34$ & $63(22.3)$ & Farmers & $12(5.2)$ \\
\hline $35-39$ & $25(8.8)$ & Others & $1(0.4)$ \\
\hline $40-44$ & $11(3.9)$ & & \\
\hline $45-49$ & $2(0.7)$ & & \\
\hline \multicolumn{4}{|l|}{ Marital status } \\
\hline Married & $273(96.5)$ & & \\
\hline Separated/Divorce & $7(2.5)$ & & \\
\hline Single & $3(1.1)$ & & \\
\hline \multicolumn{4}{|l|}{ Number of children } \\
\hline 1 & $59(20.9)$ & & \\
\hline 2 & $84(29.7)$ & & \\
\hline 3 & $55(19.4)$ & & \\
\hline 4 & $49(17.3)$ & & \\
\hline$\geq 5$ & $36(12.8)$ & & \\
\hline \multicolumn{4}{|l|}{ Ethnicity } \\
\hline Yoruba & $222(78.4)$ & & \\
\hline Hausa & $30(10.6)$ & & \\
\hline Tiv & $11(3.9)$ & & \\
\hline Nupe & $8(2.8)$ & & \\
\hline Fulani & $4(1.4)$ & & \\
\hline Igbo & $3(1.1)$ & & \\
\hline Others & $5(1.8)$ & & \\
\hline \multicolumn{4}{|l|}{ Religion } \\
\hline Islam & $257(90.8)$ & & \\
\hline Christianity & $26(9.2)$ & & \\
\hline \multicolumn{4}{|l|}{ Level of education } \\
\hline No formal education & $50(17.7)$ & & \\
\hline Primary & $87(30.7)$ & & \\
\hline Secondary & $114(40.3)$ & & \\
\hline Tertiary & $32(11.3)$ & & \\
\hline
\end{tabular}

As seen in Table 2, majority, 254(89.8\%), of the respondents were aware of antenatal services with the health worker constituting the commonest source of informa- tion among the respondents. More than three-quarters, $259(91.5 \%)$, had perceived need for ante-natal care during pregnancy. 
Table 2: Respondents' awareness, knowledge and perception of ante-natal/delivery services

\begin{tabular}{|c|c|c|}
\hline Variable & \multicolumn{2}{|c|}{ Frequency (\%) } \\
\hline Awareness of ANC services & & \\
\hline Aware & \multicolumn{2}{|l|}{$254(89.8)$} \\
\hline Not Aware & \multicolumn{2}{|l|}{$29(10.2)$} \\
\hline \multicolumn{3}{|l|}{ Source of information* } \\
\hline Health worker & \multicolumn{2}{|l|}{$91(35.8)$} \\
\hline Relative & \multicolumn{2}{|l|}{$43(16.9)$} \\
\hline Husband & \multicolumn{2}{|l|}{$37(14.6)$} \\
\hline Television & \multicolumn{2}{|l|}{$27(10.6)$} \\
\hline Radio & \multicolumn{2}{|l|}{$23(9.1)$} \\
\hline Friend & \multicolumn{2}{|l|}{$14(5.5)$} \\
\hline Newspapers & \multicolumn{2}{|l|}{$14(5.5)$} \\
\hline Others & \multicolumn{2}{|l|}{$41(16.1)$} \\
\hline Knowledge of ANC activities & Yes $(\%)$ & No $(\%)$ \\
\hline Abdominal examination & $213(83.9)$ & $41(16.1)$ \\
\hline Iron folates supplementation & $206(81.1)$ & $48(18.9)$ \\
\hline Blood pressure monitoring & $205(80.7)$ & $49(19.3)$ \\
\hline Blood test & $202(79.5)$ & $52(20.5)$ \\
\hline Administration of tetanus vaccine & $189(74.4)$ & $65(25.6)$ \\
\hline Weight/Height measurement & $187(73.6)$ & $67(26.4)$ \\
\hline Urine test & $186(73.2)$ & $68(26.8)$ \\
\hline Health education on pregnancy & $169(66.5)$ & $85(33.5)$ \\
\hline Anti-malaria prophylaxis & $151(59.4)$ & $103(40.6)$ \\
\hline HIV counseling and Testing & $137(53.9)$ & $117(46.1)$ \\
\hline \multicolumn{3}{|l|}{ Knowledge score } \\
\hline Poor $(0-4)$ & \multicolumn{2}{|l|}{$76(26.9)$} \\
\hline Fair $(5-7)$ & \multicolumn{2}{|l|}{$69(24.4)$} \\
\hline Good (8-10) & \multicolumn{2}{|l|}{$138(48.8)$} \\
\hline \multicolumn{3}{|l|}{ Perceived need for ante-natal care } \\
\hline Yes & \multicolumn{2}{|l|}{$259(91.5)$} \\
\hline No/Don't know & \multicolumn{2}{|l|}{$24(8.5)$} \\
\hline \multicolumn{3}{|l|}{ Perceived person to be at delivery } \\
\hline Doctor & \multicolumn{2}{|l|}{$127(44.9)$} \\
\hline Trained Nurse/midwife & \multicolumn{2}{|l|}{$123(43.5)$} \\
\hline Relatives/friends & \multicolumn{2}{|l|}{$11(3.9)$} \\
\hline Traditional Birth Attendant & \multicolumn{2}{|c|}{$7(2.5)$} \\
\hline No one & \multicolumn{2}{|c|}{$11(3.9)$} \\
\hline Others & $4(1.4)$ & \\
\hline
\end{tabular}

*Multiple responses

Table 3 also showed that more than three-quarters, $253(89.4 \%)$, of the respondents utilized ante-natal care services during their last pregnancy with about twothirds, 161 (63.6\%), utilizing a public health facility in the community for such services. However, only 127 $(50.2 \%)$ of them made their first visit to ANC clinic within the first trimester. For delivery services, just about half,
145(51.2\%), had their babies delivered in a government hospital in their last pregnancy while $45(15.9 \%)$ of them had their babies delivered at home or at the traditional birth homes. For about two-thirds, 177(62.5\%), of the respondents, trained nurses/midwives were at the delivery, while only less than a quarter, 64(22.6\%) had doctors conduct their delivery. About 15\% of the respondents had no skilled attendant at the delivery of their last child. 


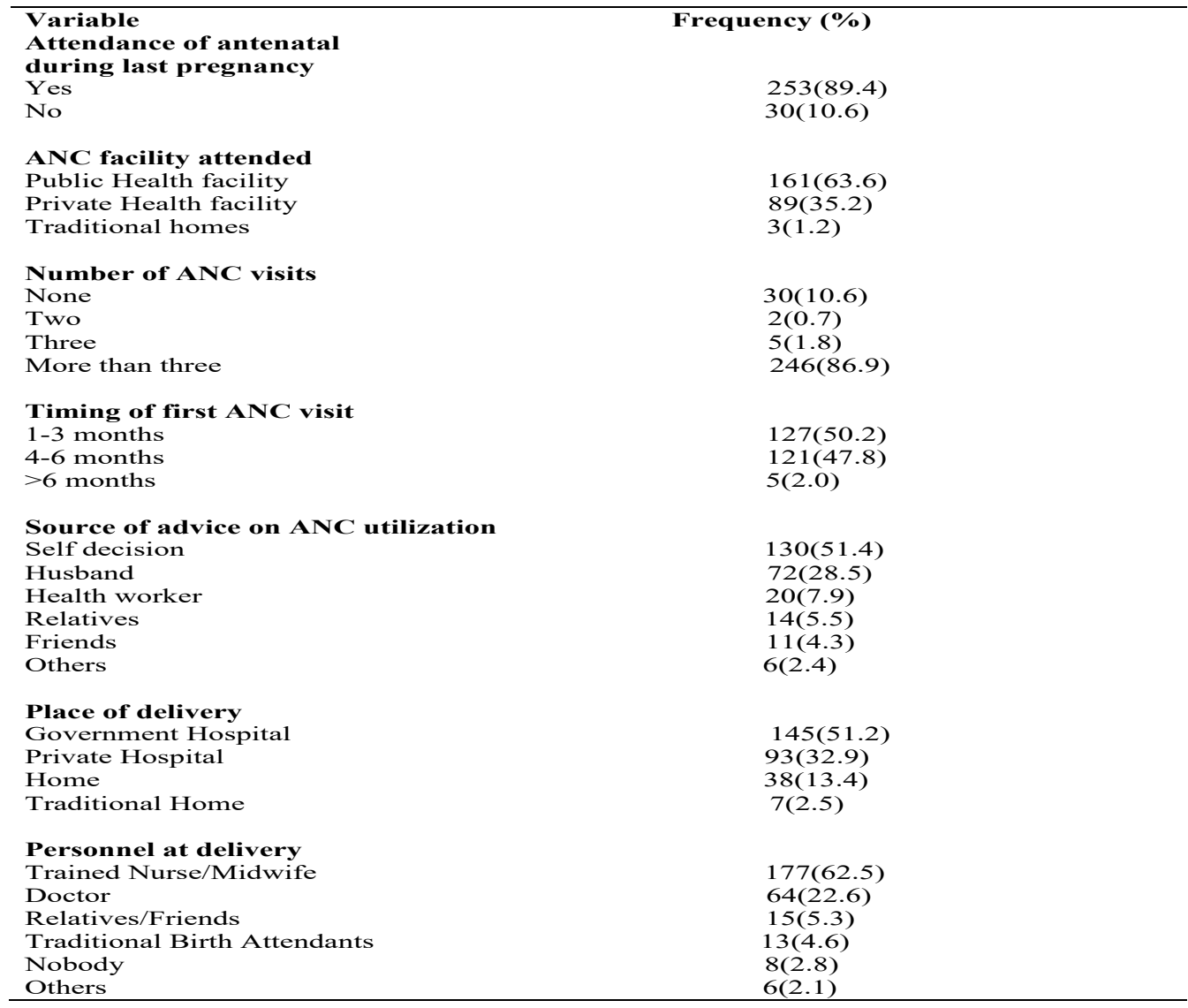

As shown in Table 4, lack of money as a barrier to utilization of ante-natal services was found to be the commonest constituting $116(41.0 \%)$. While age of the women was found not to be a significant barrier to utilization of antenatal services, level of education, employment status and parity were found to be statistically significant for utilization of ante-natal services. Respondents with higher educational exposure utilized antenatal care services more than those with lower or no education. This observed difference was significant with p value of 0.000 . Also, those who are gainfully employed utilized ante-na- tal services more than those who were not employed as more than a quarter of the unemployed, 13(26.0\%), did not go for ante-natal clinics compared with only less than a tenth, 17(7.3\%), among the employed respondents. The women with higher number of children had better utilization than those with lower number of children. In other words, the higher the parity, the better the utilization of ante-natal services among the respondents as only $3(3.5 \%)$ of respondents with $\geq 4$ children did not utilize ante-natal services. The observed difference was also found to be statistically significant with a $\mathrm{p}$ value of 0.027 . 
Table 4: Barriers to ANC utilization and delivery services among respondents

\begin{tabular}{|c|c|c|c|c|}
\hline $\begin{array}{l}\text { Variable } \\
\text { Barriers to ANC utilization }\end{array}$ & Yes (\%) & No (\%) & $\chi^{2}$ & P value \\
\hline $\begin{array}{l}\text { Barriers to ANC utilization } \\
\text { Lack of money }\end{array}$ & & & & \\
\hline & $116(41.0)$ & $167(59.0)$ & & \\
\hline Traditional belief & $80(30.4)$ & 197(69.6) & & \\
\hline Distance to health facility & $46(16.3)$ & 237(83.7) & & \\
\hline Poor attitude of health workers & $40(14.1)$ & 243(85.9) & & \\
\hline Long waiting time at health facility & $44(15.5)$ & $239(84.5)$ & & \\
\hline Lack of transport fee & $24(8.5)$ & $259(91.5)$ & & \\
\hline Inadequate trained staff & $9(3.2)$ & $274(96.8)$ & & \\
\hline Not want to go alone & $7(2.5)$ & $276(97.5)$ & & \\
\hline No husband permissions & $3(1.1)$ & $280(98.9)$ & & \\
\hline \multicolumn{5}{|l|}{ ANC attendance and age(yrs) } \\
\hline $15-19$ & $7(63.6)$ & $4(36.4)$ & & \\
\hline $20-24$ & $74(89.2)$ & $9(10.8)$ & & \\
\hline $25-29$ & $80(90.9)$ & $8(9.1)$ & & \\
\hline $30-34$ & $56(88.9)$ & $7(11.1)$ & 6.427 & $0.377 *$ \\
\hline $35-39$ & $24(96.0)$ & $1(4.0)$ & & \\
\hline $40-44$ & $10(90.9)$ & $1(9.1)$ & & \\
\hline $45-49$ & $2(100.0)$ & $0(0.0)$ & & \\
\hline \multicolumn{5}{|c|}{ ANC attendance and level of education } \\
\hline None & $34(68.0)$ & $16(32.0)$ & & \\
\hline Primary & $82(94.3)$ & $5(5.7)$ & & \\
\hline Secondary & $105(92.1)$ & $9(7.9)$ & 27.01 & $0.000 *$ \\
\hline Tertiary & $32(100.0)$ & $0(0.0)$ & & \\
\hline \multicolumn{5}{|l|}{$\begin{array}{l}\text { ANC attendance and employment } \\
\text { status }\end{array}$} \\
\hline Employed & $216(92.7)$ & $17(7.3)$ & & \\
\hline Unemployed & $37(74.0)$ & $13(26.0)$ & 15.19 & $0.000^{*}$ \\
\hline \multicolumn{5}{|l|}{$\begin{array}{l}\text { ANC attendance and number of } \\
\text { children }\end{array}$} \\
\hline 1 & $53(89.8)$ & $6(10.2)$ & & \\
\hline 2 & $69(82.1)$ & $15(17.9)$ & 9.17 & $0.027 *$ \\
\hline 3 & $49(89.1)$ & $6(10.9)$ & & \\
\hline$\geq 4$ & $82(96.5)$ & $3(3.5)$ & & \\
\hline
\end{tabular}

*Yates correction

\section{Discussion}

In this study, the age range of respondents was found to be from $15-45$ years while the mean age of respondents was found to be 27.9 with a standard deviation of 6.0 years. Majority of them, 96.5 percent were married. More than three-quarter of respondents $(89.8 \%)$ were aware of antenatal services in this community and majority of respondents, (90.1\%) also had knowledge about the presence of antenatal and delivery services in the community. This is similar to the findings in a study carried out at Sagamu, South West Nigeria by Iyaniwura et al where 87\% of respondents were aware of antenatal facilities in the community. ${ }^{13}$ This level of awareness is high and could be attributed to the high proportion of the women with formal education. About eighty-two percent of the respondents had one form of formal education or the other. Also the community is a semi-urban one with access to basic social amenities and mass media.

Among respondents that were aware of antenatal services, less than $50 \%$ of them had good knowledge of the activities carried out during antenatal service. This may be due to the fact that although a high proportion of the women had some form of formal education, only $51.6 \%$ of them had secondary education and above. This finding is in contrast to the study carried out in Ilorin by Adewoye in which over two thirds of the respondents had good knowledge on ANC activities. ${ }^{14}$ However, close to $66 \%$ of them in that study had secondary education and above.

The qualitative aspect of this study also gave insight into some of their practices with regards to antenatal and delivery services in this community. Findings from the focus group discussions (FGD) carried out revealed that many of the female participants are motivated to use ANC services. They have positive attitudes towards utilization of these services and to some extent have correct knowledge of some of the activities carried out in the ANC clinic. For example, one participant stated that "Antenatal care should start from when one knows she is pregnant to ensure that baby is in good condition and to receive nutritional advice"

And another participant said "They (health workers) examine our abdomen; check our blood pressure and weight. We also sing African Health Sciences Vol 16 Issue 4, December, 2016 
and dance and they tell us to do light exercises". This shows that some of the women have some knowledge about the activities of ANC.

Also, above $80 \%$ of eligible respondents in Afon community were engaged in one form of employment or the other while only $17.7 \%$ were unemployed. This finding is also similar to what was obtained in the Iyaniwura study where $14.8 \%$ of respondents were not gainfully employed. ${ }^{13}$ This is in contrast with the finding in a study conducted in Bangladesh where only $31.4 \%$ of the respondents were engaged in gainful employment. ${ }^{15}$ Thisdifference may be attributable to the different socio-cultural environment in the two places as women are more dependent on their spouses in that part of the world.

Report of antenatal care attendance is generally high in this study with $89.4 \%$ of respondents attending ANC in their last pregnancy. This finding is similar to what was found in Ibadan by Dairo et $\mathrm{al}^{16}$, in the Sagamu study ${ }^{13}$ and in an Uganda study by Kiwuwa et $\mathrm{al}^{17}$ where utilization of ANC services was found to be $76.8 \%, 84.6 \%$ and $94.4 \%$ respectively. This is in contrast to what was found in Kano where only $24.7 \%$ of the women had visited a clinic or facility for ANC at least once during their most recent pregnancy. ${ }^{12}$ This disparity may be due to the different socio-cultural circumstances in the different parts of the country and can also explain the vast difference in the maternal mortality ratios in these parts of the country.

However, close to half of respondents, $(49.8 \%)$ attended ANC clinic for the first time during their last pregnancy in the second and third trimesters when it might be too late to benefit maximally from some of the antenatal services. Evidence has shown that early risk assessment during pregnancy can help to reduce significantly maternal mortality and morbidity. ${ }^{2}$

Also, majority of respondents, $86.9 \%$ made three or more visits to the ANC clinic. The most recent World Health Organization recommendation is to promote a reduced but goal-oriented antenatal clinic visit which should be a minimum of four visits. ${ }^{18}$ This finding is in contrast to what was obtained in a study by van Eijk at al in Kenya ${ }^{19}$ where only half of the women attended the recommended 4 visits as well as Kiwuwa study in which only $37.1 \%$ reported 4 visits or more. ${ }^{17}$ This difference might be due to the fact that the Kenyan and the Ugandan studies were among rural women but this study was conducted in a semi-urban community.

African Health Sciences Vol 16 Issue 4, December, 2016
Most of the women that attended ANC in this study reported to have received evidenced based services which include antimalaria prophylaxis, administration of anti tetanusToxoid, counselling on HIV/AIDS, prescription of iron and folates and health education on danger signs of pregnancy. This is in congruent to the findings from Adewoye study carried out in a similar environment. ${ }^{14}$ This finding is not unexpected considering the relatively high level of attendance at ANC and the high literacy level among the women in the community.

It was also discovered from this study that among the respondents, some of them, $15.9 \%$ delivered their babies at home or in traditional homes with no skilled personnel in attendance. Absence of skilled attendant at delivery makes timely treatment of life threatening complications difficult. Although this proportion is relatively lower than the world average of $34 \%$ from a World Health Organization report of 2008. ${ }^{10}$ The proportion of women in this study who had skilled attendant (doctor, nurse or trained midwife) at birth was found to be high at $85.1 \%$.

This in contrast to the findings from a study carried out in Kano, Northern Nigerian where only 11.25 percent were attended to by professional trained provider. ${ }^{12}$ This proportion of skilled attendants at birth is very important as it goes a long way to reduce maternal deaths from birth complications as these attendants are trained to recognize serious complications that require more specialized emergency care..$^{20}$ Also, it is used frequently by countries as an indicator of progress towards Millennium development Goal 5, which aims to improve maternal health. ${ }^{20}$

Majority of respondents, $63.6 \%$ that attended antenatal care service during their last pregnancy utilized the government health facility. Among those that delivered their babies in health facilities, $51.2 \%$ did so in the government hospitals. This is similar to the findings in the Sagamu's study where $60.2 \%$ and $54.4 \%$ utilized government facility for ANC and delivery service respectively. ${ }^{16}$ This may be because the services rendered in the government hospitals are highly subsidized because of the commencement of the community health insurance policy in Afon community.

Several factors were identified in this study as the barriers to utilization of antenatal and delivery services among these women. The factors identified include lack of mon- 
ey to pay for services, traditional beliefs, distance from health facility, long waiting time, poor attitudes of health workers inadequate trained staff, and no permission from husbands in that order. This is similar to findings in some similar studies conducted in Nigeria, some other African countries and in rural Bangladesh. ${ }^{13,14,16,19,21,22}$

Issue of financial constraints, traditional beliefs, cultural inhibitions and ignorance about importance and need for ANC and delivery also emerged from the FGD - Examples are these statements from some of the participants. "Some women do not go to the health facility for ANC because of the money that they (health worker) may request for."

"I cannot go to the health facility for care during pregnancy because am not sick"

".......... some women do not want male health workers to do vaginal examination on them but I prefer anyone"

"Some people believe is only God that can help to deliver and so prefer to stay back at home for delivery, besides it is very comfortable and at no cost"

"We don't like to go to the hospital because of language barrier"

"If there is no approval from husband, we would not go to seek care"

"Some women prefer traditional home because if there is difficulty during delivery, spiritual intervention can be obtained"

Also, both female and male groups pointed the issue of poor attitude of health workers and distance from health facilities as some of the barriers to utilization of maternal health services. Such statements like:

"Poor attitude of health workers like shouting on the pregnant woman and forcing us to walk up and down"

"Some of the women are shy. Sometimes they panic due to the bebaviour, attitudes and utterances of the nurses"

"Sometimes labour starts at night and the hospital are far away and there is no transportation"

Some of these reasons such as expense of care, home comfort, no permission from husbands, and poor attitude of health workers were also reported from the study from Kano by Doctor et al. ${ }^{12}$

These findings are also consistent with some of the findings in a similar study by Titaleyet al in Indonesia. ${ }^{23}$ They found that financial difficulty and lack of awareness about the importance of maternal and child health services were major issues for women who did not attend any antenatal or postnatal care services as recommended. ${ }^{23}$ This has really brought forth other barriers in utilization of maternal health services among these women in this community.
The association between the age of respondents and awareness or utilization of antenatal care services was not statistically significant in this study. This is similar to the findings from Chakraborty et al, Babalola et al study, and Nwakoby BN. ${ }^{15,24,25}$ However it is in contrast to the findings of similar studies carried out in Ibadan and Sagamu where respondents older than 25 years utilized antenatal services more and those less than 20 years did not use ANC services respectively. ${ }^{13,16}$

Level of education of respondents and their level of awareness of antenatal care services as well as the utilization of the services was found to be statistically significant with p- values of 0.0000 each. This finding is consistent with the results of several local and international studies in which strong association has been demonstrated between the level of education and utilization of maternal health care services. ${ }^{13,15,16,24,26,27,28,29}$ This is not unexpected as education has been shown to improve awareness because of better exposure and access to information. It also serves as means of improved ability to earn more money which is proxy for higher health seeking behaviour.

There was also a statistically significant relationship between the level of education of respondents in this study and their perceived need of antenatal care during pregnancy, $\mathrm{p}=0.0009$. This is in congruent with a similar study carried out in Anambra, South East Nigeria where the educational level of respondents was significantly associated to their perceived need of $\mathrm{ANC}$ with a $\mathrm{p}$-value of $0.000 .^{30}$

There was a statistically significant relationship between employment status and attendance at antenatal clinic and utilization of health facility for delivery with p-value of 0.0000 and 0.0002 respectively. Women that were gainfully employed were more likely to attend ANC clinic and deliver in the health facilities.

High socio-economic status has been identified as a significant predictor of utilization of antenatal and delivery services. This evidence has been shown in different studies carried in Nigeria, ${ }^{12,13,24}$ other African countries, ${ }^{19,21,31}$ in some parts of Asia such as Indonesia and Bangladesh. ${ }^{22}$, 23,32 However, in a study carried out in Eastern Sudan, the socio-economic status of respondents could not be investigated in relation to the level of utilization of ANC and delivery service because of practical difficulties. ${ }^{33}$

African Health Sciences Vol 16 Issue 4, December, 2016 
The type of occupation of husbands of respondents was found to be statistically significantly associated with place of delivery of the last child of respondents with a p-value of 0.0000 . Respondents whose husbands were civil servants delivered in the health facility more frequently than those whose husbands were artisans or farmers. This is consistent with what was obtained in the South Western Nigerian study ${ }^{16}$ and the Eastern Sudan study ${ }^{33}$ as well as in rural Bangladesh. ${ }^{15}$ The reason is not far fetched as majority of those that are civil servants had secondary education and above and this high literacy among the husbands is a positive predictor of utilization of maternal health services. Also husbands' occupation goes a long way in determining family income and socio-economic status of the family which in turn affect utilization of health services. This is aside the fact that they have a reasonably consistent source of income and are more likely to earn better.

There was no relationship with parity of respondents and choice of place for delivery, $\mathrm{p}$-value was found to be 0.587. This is quite surprising as previous studies from Delta, Southern Nigerian showed association between parity and utilization of ANC services. ${ }^{20}$ However, it is consistent with the finding from Babalola et al study and Chakraborty et al where results showed a U-shaped relationship with number of previous pregnancies and use of health services for maternal morbidities. ${ }^{15,24}$

\section{Conclusion/recommendation}

There was high level of awareness and utilization of antenatal care services among women of reproductive age in Afon community both from the quantitative and qualitative data collected. Raising the stakes for utilization of ANC during pregnancy can be achieved by collaborating with the traditional and religious leaders in this community. More qualified staff and voluntary health workers can be recruited from the community to champion these enlightenment campaigns. Educational exposure (subsidized by the government) and financial empowerment of women will equally go a long way to also strengthen utilization of antenatal and delivery services.

\section{Conflict of interest}

None to declare.

\section{References}

1. Obionu CN. Maternal Health Service. In: Primary Health Care for Developing Countries. 2nd ed. Enugu: African Health Sciences Vol 16 Issue 4, December, 2016
Institute For Development Studies; 2007. 219-30.

2. Park K. Preventive Medicine in Obstetrics, Paediatrics and Geriatrics. Textbook of Preventive and Social Medicine. 17th ed. Jabalpur: M/s Banarsidas Bhanot; 2002. 359-98. 3. Olise P. Maternal and Child Health. Primary Health Care for Sustainable Development. 1st ed. Abuja: Ozege Publications; 2007. 142-66.

4. WHO. Maternal Mortality. 2008 Available from:http:/ / www.who.int/mediacentre/factsheets/fs348/en/ [Accessed 04/05/2011]

5. WHO. Newborn: Reducing Mortality. 2009 Available from:http://www.who.int/mediacentre/factsheets / fs333/en/ [Accessed 04/05/2011].

6. WHO. World Health Report 2005: Make Every Mother and Child Count, Geneva, World Health Organization, 2005:2-68

7.HERFON. Maternal Health in Nigeria. Nigerian Health Review. Abuja: Kenbim Press Limited; 2006. 103-20.

8. FMOH. Integrated Maternal, Newborn and Child Health Strategy; 2007: 4-85.

9. FMOH. Saving Newborns lives in Nigeria: Situation Analysis and Action Plan for Newborn Health. Abuja; 2009: 8-46.

10. WHO. Skilled Birth Attendants. 2008. Available from:http://www.who.int/making_pregnancy_safer/events $/ 2008 / \operatorname{mdg} 5 /$ factsheet_sba.pdf[Accessed 04/05/2011]

11. National Population Commission (NPC) [Nigeria] and ICF Macro.2009. Nigeria Demographic and Health Survey 2008. Abuja, Nigeria: National Population Commission and ICF Macro.

12. Doctor H, Findley S, Dahiru T. Use of Antenatal Services and Delivery Care among Women in Northern Nigeria. Available from: http://paa2010.princeton.edu/ papers/101231 [Accessed 08/04/2011]

13. Iyaniwura CA, Yussuf Q. Utilization of Antenatal Care and Delivery Services in Sagamu, South Western Nigeria. Afr J Reprod Health 2009;13(3):111-22. PubMed 14. Adewoye KR. Knowledge and Utilization of Maternal and Child Health Services among Women of Reproductive Age Group in Ilorin East LGA [MPH]. Ilorin: University of Ilorin; 2011.

15. Chakraborty N, Islam MA, Chowdhury RI, Bari W, Akhter HH. Determinants of the Use of Maternal Health Services in Rural Bangladesh. Health Promot Int. 2003; 18(4):327-37. PubMed

16. Dairo MD, Owoyokun KE. Factors Affecting the Utilization of Antenatal Care Services in Ibadan, Nigeria. Benin Journal of Postgraduate Medicine. 2010; 12 (1).3-14. 
17. Kiwuwa M, Mufubenga P. Use of Antenatal Care, Maternity Services, Intermittent Presumptive Treatment and Insecticide Treated Bed Nets by Pregnant Women in Luwero District, Uganda Malaria Journal. 2008 March 2008;7:44-49 PubMed .

18. WHO. Statement of Antenatal Care. In: Research RHa, editor; 2011. 1-2.

19. van Eijk A, Bles H, Odhiambo F, Ayisi J, Blokland I, Rosen D, et al. Use of Antenatal Services and Delivery Care Among Women in Rural Western Kenya: A Community Based Survey. Reproductive Health. 2006 April 2006;3(2).1-11. PubMed

20. UNICEF. Maternal and Newborn Health In: Moccia P, editor. State of the World Children 2009 Colorcraft of Virginia, Inc; 2008. 50-5.

21. Mrisho M, Obrist B, Schellenberg JA, Haws RA, Mushi AK, Mshinda $\mathrm{H}$, et al. The use of antenatal and postnatal care: Perspectives and experiences of women and health care providers in rural southern Tanzania. BMC Pregnancy Childbirth. 2009;9:10-16.

22. Amin R, Shah NM, Becker S. Socioeconomic Factors Differentiating Maternal and Child Health-Seeking Behavior in Rural Bangladesh: A Cross-Sectional Analysis. Int J Equity Health. 2010; 9:9.

23. Titaley CR, Hunter CL, Heywood P, Dibley MJ. Why Don't Some Women Attend Antenatal and Postnatal Care Services?: A Qualitative Study of Community Members' Perspectives in Garut, Sukabumi and Ciamis Districts of West Java Province, Indonesia. BMC Pregnancy and Childbirth. 2010; 10:61.

24. Babalola S, Fatusi A. Determinants of Use of Maternal Health Services in Nigeria - looking beyond individual and household factors. BMC Pregnancy and Childbirth 2009 September 2009; 9:43-55 PubMed .
25. Nwakoby B. Use of Obstetric Services in Rural Nigeria. J R Soc Health. 1994; 114(3):132-6. PubMed

26. Awusi V, Anyanwu E, Okeleke V. Determinants of Antenatal Care Services Utilization in Emevor Village, Nigeria. Benin Journal of Postgraduate Medicine. 2009;11:22021.

27. Rahman MM, Haque SE, Zahan MS. Factors Affecting the Utilisation of Postpartum Care Among Young Mothers in Bangladesh. Health Soc Care Community. 2011;19(2):138-47.

28. Jimoh AA. Utilization of Antenatal Care Services at the Provincial Hospital, Mongomo, Guinea Equatoria. Afr J Reprod Health. 2003 2003;7:48-54. (3 PubMed)

29. Egbewale B, Bamidele J. Demographic Profile of Mothers and Their Utilization of Maternal Health Care Services in Osun State, Nigeria. Niger Postgrad Med J. 2009;16(2):132-8.

30. Anikwe C. Utilization of Antenatal Care and Delivery Services by Women of Reproductive Age in Anambra East Local Government Area of Anambra State. Ilorin: University of Ilorin; 2008.

31. De Allegri M, Ridde V, Louis VR, Sarker M, Tiendrebeogo J, Ye M, et al. Determinants of Utilisation of Maternal Care Services After the Reduction of User Fees: A Case Study from Rural Burkina Faso. Health Policy. 2010; 99(3):210-8. PubMed

32. Chakraborty N, Islam MA, Chowdhury RI, Bari W. Utilisation of Postnatal Care in Bangladesh: Evidence from a Longitudinal Study. Health Soc Care Community. 2002; 10(6):492-502.

33. Ali AA, Osman MM, Abbaker AO, Adam I. Use of Antenatal Care Services in Kassala, Eastern Sudan. BMC Pregnancy Childbirth. 2010;10: 67-71. 